Metadata of posters in XML schema

\title{
Metadata of posters in XML schema
}

\author{
Margit Némethi-Takács \\ Department of Library Informatics, Faculty of Informatics, University of Debrecen \\ Debrecen, Hungary \\ takacs.margit@inf.unideb.hu
}

\begin{abstract}
The number of electronic archives holding image documents such as posters is increasing besides traditional, textual materials. It is definitely true for digitized poster collections that the use of metadata is essential for their operation as with the help of metadata electronic documents can be efficiently sorted and retrieved. The research study presents the main characteristics of posters, summarises the difficulties in their technical processing, and describes the XML-based schema storing the metadata of posters.
\end{abstract}

Keywords: posters, metadata, bibliographic description, description schema

\section{Introduction}

Though books and journals have been determinant document types in libraries since centuries, the collection interest of libraries can include other document types too. Special collections can be organized from certain document types depending on the number of documents where ephemera can be placed as well. The printed materials of everyday life, generally regarded as having little or no permanent value because they are produced in large quantities or in disposable formats for a specific limited use. The category includes pamphlets, handbills, leaflets, broadsides, position papers, minutes of meetings, information sheets, bulletins, newsletters, posters, etc. Posters represent the most investigated and often borrowed part of this publication type.

During conducting research in printed poster collections we, however, can face difficulties, since it is not sure that it is enough for us to know the title and author of the work. In several cases it might be even necessary to have a look at the image itself on poster. In 
order that a relevant work should be found we must look at more posters, which can be rather problematic in regard to storage and type of posters. On the one hand printed posters have a big size in general, therefore their viewing demands a lot of room. On the other hand their storage ideally takes place in chests of drawers, many times these documents, however, are put into letter files or are stored in boxes. In the latter case not only the viewing of posters is problematic, but also the orientation among boxes. Preparing the digitized version of posters and organizing them into an electronic collection can be a solution to this task.

It is definitely true for digitized poster collections that the use of metadata is essential for their operation as with the help of metadata electronic documents can be retrievable. The problem arises from the fact that libraries taking on cataloguing apply a different set of metadata elements. Of course the most significant bibliographic data such as title, author, publication, number of pages are recorded, but the presentation of data which are typical of posters is undertaken only by a few libraries. However the processing of library documents should be based on principles which are independant of country, language and library type. Concerning great part of library documents the IFLA ISBD program provides consistent principles, on the contrary the principles regulating the bibliographic description of posters are still missing. Starting from these assumptions I have searched answers to the following research questions:

- $\quad$ concerning printed posters which secondary descriptive data can be used for making „international standard bibliographic description” about posters corresponding to ISBD,

- what metadata is needed for cataloguing the digitized posters?

- $\quad$ How can storage of these metadata elements be realized in computer-based systems?

Corresponding to this I determined the data elements which are necessary for the bibliographic description and identification of printed posters, the order of data elements and 
the punctuation. Thus applicable principles of bibliographic description of printed posters have been determined based on the ISBD rules.

Bibliographic data of digitized posters were decided at the following step. Since mode of recording of digitized posters is different from that of printed posters, therefore new data elements came to the front. Such data elements can be system requirements needed for displaying an image, file characteristics of digitized image, technique used for creating the digitized image, etc.

Finally I analysed the storage of the determined data elements in computer-based systems. Both international and national practices show that XML schema is applied to the storage of metadata. I have studied a number of descriptive schemas necessarily, among others Metadata Object Description Schema (MODS) too. Printed, digitized and electronic documents can be described using the MODS. But I have found that certain data determined by me do not appear in this description schema. Such as polarity which can be important in some cases. Graphic posters can be put into the category of visual documents rather than that of textual documents, therefore it can be of vital importance what is the relationship of the colours on digitized poster to the colours on original one. The quality of digitized image can be influenced by the number of times an image on poster has been transferred from one carrier to another. Therefore I thought that generation metadata is important. Form and extent of digitized image can be given in <physicalDescription> metadata, but in my opinion it has to be connected with a filename too. After all I have found that MODS have deficiencies concerning the data of electronic documents. For this reason I decided to elaborate a schema which could be used for the bibliographic description of posters.

In this study the Poster Metadata Description Schema (PoMeDS) will be presented that we have developed. It is an XML-based schema working with the metadata elements of (printed and digitized) posters determined by us. 


\section{Posters in public libraries}

Collections of ephemera comprise one type of special collections. The material belonging to the collective term of ephemera is diverse and varied. This document type records the historical events just as it follows also the occurrences of everyday life up-to-date.

This type of publications has rarely gained independent status in public libraries; rather it has been presented as part of other collections. In contrast to traditional library documents (books and journals) this type of print has been more neglected over time. Considering their content these prints do not have either such a great popularity as books and journals have. According to certain views one or few page-long prints, thin booklets can not contain any important information and knowledge which is worth noting or preserving. Among these rather plain prints there are significant and remarkable works which contribute to getting to know more details about the everyday life of a historical period.

Majority of ephemera has a peculiar bibliographical and resource value. We can state that 'the resource value and importance of ephemera in libraries increase in direct proportion to the time that passed since their creation'. It is partly explained by the low number of copies in general and by the data in ephemera which can be discovered nowhere else or can be difficult to find'. (Tóth, 1968) In many cases the existence of merely one document can help us to close a research project or it can play a significant role in answering given questions.

Posters represent one of the most investigated and often borrowed materials of these prints. An outstanding ephemera collection can be an indispensable source of historical and biographical research, particularly in the field of cultural, industrial and art history etc. For these prints were produced to communicate political fights of the centuries of our history, news and events of revolutions and counter revolutions and decrees to a mass of people.

We can meet this type of publication in various public collections all over the world. Owing to legal deposit a wide range of posters has enriched main part of great national 
libraries, but corresponding to the type of collection they can be accessible in other public collections too. For example the noteworthy masterpieces of commercial art are present in collections of commercial art. Documents characterizing a historical period can be found in museums of history or local history; graphic posters are available in collections of fine arts.

\section{What is a poster?}

A proper definition was provided by one of the outstanding French artists of the genre, Cassandre for the above mentioned question. He says that: „The poster is a tool, a tool for the tradesman to communicate his message to the consumer, its role is similar to the telegrapher's when we send a telegram: he does not initiate the messages, he transmits them. Nobody asks his opinion, but he is expected to convey a lucid and punctial message. Clarity and powerful expression are the most important."

We can meet posters as we know them today only after the invention of printing. In the beginning mainly textual posters appeared in the streets, later these textual messages were complemented with pictures. Concerning graphic posters a breakthrough was taking place when the genre joined Alois Senefelder's invention, the lithography. The demands of everyday life have made the genre of posters widely spread.

The purely textual messages of early days which appeared after the invention of printing, usually published information of public interest. This is how new laws, issues of public administration and war news became known to the public. We know of posters connected to auctions and military conscriptions. The first posters emerged in the form of small sized flyers and they were related to trading.

Owing to the fast and cheaper lithographic procedure the litographed posters appeared in the streets of big cities painted with highly artistic care. This new type of pictorial poster first has become an effective visual tool for trading, industry and culture, later of politics as well. By the end of the last century trade posters prevailed and huge posters appeared. However we 
can not call them artistic with the best intention either. Their only purpose is attracting customers into the shops and selling the advertised products. Apart from the elective rounds, the two other types of posters - cultural and political ones - nearly have disappeared from the streets for today.

We can distinguish three types of posters from the aspect of formal characteristic; namely, textual posters, pictorial ones and textual-pictorial ones. In the following the last two types of posters are put into the category of graphic ones. In the case of textual posters the written content has an importance, while regarding graphic posters the emphasis is put mainly on the represented picture, although the text complementing the picture can also have a significant role.

The textual poster is a big placard produced with one or more colour-printing usually on one of its sides. It is a document type which contains most often punctual, detailed information and a great number of data. Mainly it was applied by a local authority or an organisation as a significant tool of informing the public. At this time its role was to communicate information to the community. Today this function has already been fulfilled by other channels of communication, therefore the number and the role of textual posters decreased a lot. Its main types are administrative, elective and political notices which provide information about programs and various economic and social events. From period to period less and less purely textual posters were present and they often merged into graphic posters. Despite its decreasing presence its role is indisputable today also.

Similarly to textual posters, illustration and text are printed on one of the sides of pictorial posters too. As a result of this we have produced a placard characterized by the general effect of picture and text. Graphic posters were created mainly with commercial and cultural objective, but irrespective of purpose each of them is characterised by attraction of attention and a brief communication. They directly express things like a painting or a graphics. The 
pictorial poster serves as a mirror of an age both in artistic and in social sense. Predominant styles and fashions of a certain period can be also realized in the applied way of expression. Besides the artistic value we can not neglect the indispensable information carrier duty that graphic poster performs as a chronicler of cultural life, commerce and politics. In former times graphic posters produced with highly artistic care were typical, for today these placards almost disappeared from streets and their place have been occupied by gigantic and huge posters.

Whether we talk about textual or graphic poster, it always has a purpose: attracting attention, providing information or persuasion by means of picture and/or text. Past events are taking shape mosaic like from pictures and text of posters, therefore through them we can get to know more about social, political events and changes happening in industry, in commerce and in cultural life. In addititon to this, graphic posters represent the precious sources of artistic life as well. As a result of this, posters are at the same time documents of cultural history and history of art forming a part of visual culture and they also reflect a historical period by virtue of their content.

\section{Difficulties with the bibliographic description of posters}

Conducting a search in poster collections is not likely to be accomplished easily because beyond the appropriate bibliographic data it is often required to look at the represented image on poster. In order that a search should be successful we need to look at several hundreds of posters, which can cause problems for us from several reasons. On the one hand printed posters have a big size in general, therefore their viewing demands a lot of room. On the other hand their storage ideally takes place in chests of drawers, many times these documents, however, are put into letter files or are stored in boxes. In the latter case not only the viewing of posters is problematic, but also the orientation among boxes. 
Owing to the development of technology this problem will be solved, using technology the digitization and the electronic storage of documents became possible, as a result of it electronic archives could be built. In the beginning primarily digital libraries were built which were based on books and journals. Slowly the significance of images and illustrations preserved in public libraries has been also realized. Therefore a growing number of databases have appeared on the web where we can find the digitized versions of images and ephemera.

Documents of digital libraries may be digital ones (documents created in electronic form originally) and digitized ones (documents produced in other than electronic form and converted from other information carrier to digital one). The digital and digitized version can be differentiated in relation to posters as well. In library field the collection, the cataloguing and the delivery of digital posters still do not have a practice, therefore we limited our research to only digitized posters now.

It is indispensable to use metadata for the operation of an electronic archive, by using them the storage and the search of digital documents can be accomplished. As our objective is to use metadata scheme that can be an effective tool for research, for this reason an appropriate metadata scheme should be used for the bibliographic description of digitized posters too. Since digitized posters are available in electronic collections, therefore we should equally take into account the data of original, printed posters and the characteristics of digitized documents in the determination of bibliographic data.

To find the suitable metadata system, first we should define the set of those data which can be used for the bibliographic description of printed posters. The ISBD/NBM can be one of the bases for standard bibliographic description of posters, thus the set of metadata used for the bibliographic description can not be complete, since not only the poster belongs to the term ,non book materials”. Although there is no standard which determines the bibliographic description and the cataloguing of printed posters, but we know guides, regulations which 
have been constructed for the cataloguing of images and graphics. The rules and guides used for the bibliographic description of posters are as follows:

- BETZ Elisabeth W. (1982). Grafic materials: rules for describing : original items and historical collections. Washington D.C.: Library of Congress. http://www.loc.gov/rr/print/gm/GraMatWP8.pdf

- ISBD(G): General International Standard Bibliographic Description (1977). London: IFLA Int. Office for UBC. http://archive.ifla.org/VII/s13/pubs/isbdg1.htm

- ISBD(NBM): International Standard Bibliographic Description for Non-Book Materials (1987). London: IFLA Universal Bibliographic Control and International MARC Programme British Library Bibliographic Services. http://www.ifla.org/files/assets/cataloguing/isbd/isbd-nbm_1987.pdf

- Varga I. (1981). Állóképek bibliográfiai leírása: útmutató. Budapest: OSZK-KMK.

Owing to the use of various guides and rules, libraries have not catalogued posters in a consistent way. The most important bibliographic data like: title and statement of responsibility, publication and number of pages are recorded everywhere, but there might be differences in respect of special aspects expressing the characteristics of posters. For that very reason - considering the peculiarities of posters - we need to develop a set of metadata elements which enables the bibliographic description of posters.

First, we have to look at those data where we can meet difficulties in bibliographic description. Such problematic areas of description can be for example title and statement of responsibility, edition and series:

- Similarly to other document types title is one of the most significant data elements in the cataloguing of posters as well, because the work will be identified by this data element besides the represented image. Nevertheless placards are documents that do 
not have a separate title. Based on guides and regulations the following practice has spread according to which the text on poster is recorded as a title.

- There are such graphic posters where text can not be read and we can see only the image itself. In that case an appropriate title should be provided in square brackets. In this respect institutions follow a different practice, since there are libraries where such works consistently receive „Poster without a title” statement, other institutions give a brief descriptive title which is typical of poster.

- Posters belong to those publications which have a minimum statement of responsibility. In the determination of the author(s) we can follow the same practice as in the case of books. It means that the person who has made the work is the creator of the intellectual content. Besides the author a contributor can take part in the construction of the intellectual content of the document, but she/he fulfils a subordinate or additional function compared to the creator. In the case of graphic posters for example the person who composes the text can be regarded as a contributor.

- Concerning posters edition statement is a bibliographic data appearing most seldom on items. It is an ordinal number and/or description indicating the edition or status of a creative work. Placards belong to those document types with only one edition in general, but there are exceptions here (like everywhere). For example such exception is a poster advertizing Törley champagne created by Géza Faragó. Originally it appeared in 1909, but it has another edition of 1924 and a reprint edition of 1986 too.

- Majority of posters is an independant document, still in small number they appear as part of a series as well. In the case of graphic posters their close connection to fine arts can be realized, for we know of such poster series whose members are related to an artist's name. These series already resemble ones which are well-known in the field of 
fine arts. Here graphic works representing the same topic are created several times for the artist's intention, by giving them a common title each separate work of art appears as part of a series. Such a creative work for example is Sadie Wendell Mitchell's poster series entitled „Girls will be girls”.

- In bibliographic description of posters inclusion of the notes area is also important and by providing this information the more punctual identification of a work will be possible. Generally, a note is added to the bibliographic record when data can not be entered in some data groups. As regards posters still there is a lot of information that we need to present only in the notes area. It can be for example the textual description of the represented image or the addition of the omitted text in the case of too long titles.

If we know those problems which emerge during cataloguing and their possible solutions, then we can more easily determine what data we should provide for the bibliographic description of posters, thus we are capable of defining appropriate principles in the field of bibliographic description of printed posters. These principles will not be presented in detail because of the restricted length of the research study.

Bibliographic data of printed posters were completed by the metadata of digitized posters. Though several secondary descriptive data of printed and digitized posters are the same, the mode of recording of digitized posters is different from that of printed posters, therefore new data elements come to the front. Such data elements can be system requirements nedeed for displaying an image, file characteristics of digitized image, technique used for creating the digitized image, etc. Taking all these into consideration the maximum of descriptive data elements has been determined regarding both printed and digitized posters. Arising from this there are data elements that are essential for the identification of documents and there are other data elements that can be omitted from bibliographic description. 
To function properly in any computer-based system metadata should be encoded for machine readability and processing. Library catalog data are encoded in various MARC formats most often. Since appearance and form of electronic documents are different from those of printed documents, therefore MARC format can not be used appropriately for storing required and sufficient descriptive data of electronic documents (but there were initiatives concerning this). Storage of bibliographic data of electronic documents has been solved in several ways, for example with the application of XML language. Both international and home practices reflect that XML schema is applied to storing metadata. I have studied several descriptive schemas, but neither of them contained the determined metadata completely. For this reason I made a decision to work out a schema which can be used for the bibliographic description of posters.

\section{Poster Metadata Description Schema}

In the elaboration of the PoMeDS the main idea was for us to follow the standard bibliographic description. Resulting from this, the elaboration of the PoMeDS was based on ISBD standards, among them we can mention ISBD/NBM and ISBD/G (General International Standard Bibliographic Description) standards and instruction guides connected to them. First of all the principles that I determined for the bibliographic description of printed posters these principles were also decided on the basis of ISBD standards - were authoritative. Since the PoMeDS includes not only the descriptive data of printed posters but that of digitized posters as well, therefore the latter have been determined too.

During the planning of the schema we intended not to prepare only a bibliographic description, but to complement it with the authoritative headings by taking into consideration the IFLA guides.

Elements applied in the schema can be categorized in the following way: 
- elements corresponding to the data elements of bibliographic description

- elements corresponding to the punctuation marks of bibliographic description

- elements specifying the structure of bibliographic description

- elements corresponding to the headings.

Elements of heading can be divided into four groups:

- authorized form of a name

- other elements

- complementary data

- punctuation marks of complementary data.

In the schema the uniform name can be the authoritative form of name of persons, that of name of geographic location, corporate bodies, meeting and titles. Concerning headings we ask the cataloger who creates bibliographic records corresponding to the PoMeDS to determine the authoritative forms of various types of names.

In PoMeDS the meaning of each metadata can be specified in several ways. Exploiting the hierarchical structure of the XML schema, additional elements were defined within metadata to be specified which have already determined the meaning of the given metadata more concretely. For example <filename>, <format>, <filesize>, <compressionratio> and $<$ location> elements appear also within < filecharacteristics > metadata. It is obvious that with the help of each additional element we can define different data.

At the same time the PoMEDS uses XML attributes also for specifying each element, for designating certain codings or controlled vocabularies and for other similar purposes. These attributes occur in beginning tag. Elements can include more than one attribute too. In the case when the values of elements must be specified, the use of attribute is a better solution than the declaration of qualifiers or new elements. 
As the defined order of elements and the accepted and consistent punctuation marks preceding data elements provide the international intelligibility and interpretation of bibliographic description, therefore the PoMeDS gives rules about the order of data elements and punctuation marks which precede them.

Since punctuation marks directly precede certain data elements thus providing their identification, so these marks can be entered as a part of the content of element too. However as punctuation marks guarantee the international interpretation of certain data elements and determine the structure of bibliographic description, for this reason these marks have been defined as an independent and empty XML element in the schema. Concerning punctuation marks it is the cataloger's task to determine those marks which are associated with concrete bibliographic data in the description, such as for example the three dots which indicate that text has been omitted in some data groups.

There are such data groups where data elements can be entered in different variation depending on their occurrence. The schema takes into account these occurrences and makes possible the choice among variations. In addition, it gives orders about certain compulsory and recurrent data elements.

The PoMeDS contains metadata arranged in a hierarchical structure. At the lowest level there are declared elements with values having PoMeDSstring, PoMeDSinteger, PoMeDSanyURI or PoMeDSgYear types. It means that an element has been created with the extension of the definition of the string, integer, anyURI or gYear simple types. Thus the values of earlier mentioned types are allowed as the content of elements. Optionally date, source, hypref, modify, language attributes can be given which belong to set of PoMeDS attributes.

Taking into consideration the international usability, the terminology of ISBD/NBM standard serves as basis for giving a name to PoMeDS elements which correspond to the data 
elements of bibliographic descriptions regarding printed posters. The names of PoMeDS elements corresponded to the parallel bibliographic elements begin with $p$ letter arising from the abbreviation of 'parallel' word in English. The name of PoMeDS elements providing the identification of digitized documents was based on the terminology of Dublin Core and VRA Core.

Supporting the bibliographic description of digitized posters, the PoMeDS is composed of two parts: we process the original document with the help of one part and the another part complements the previous one with data characterizing the digitized version.

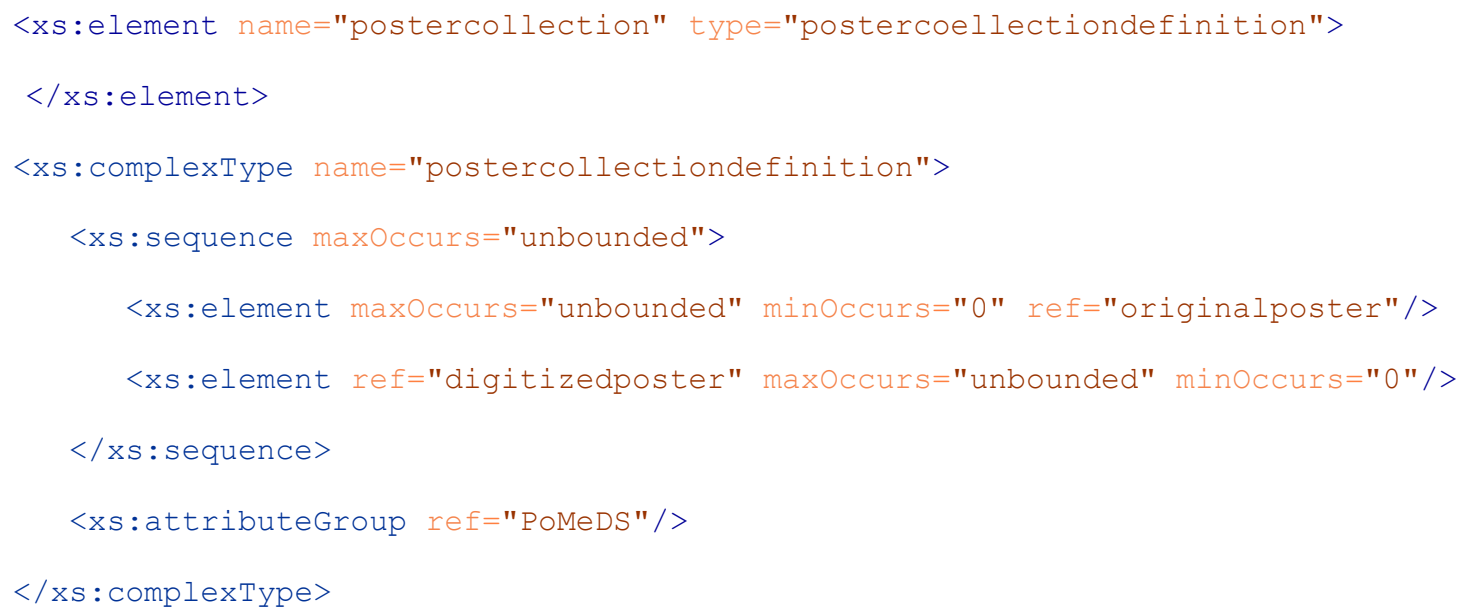

The description of the original document (originalposter) is divided into twelve major units according to the data groups and the headings of bibliographic description:

$<$ mainentry $>$ includes the authoritative form of corporate bodies, name of persons and titles on the basis of which the given bibliographic description is searchable.

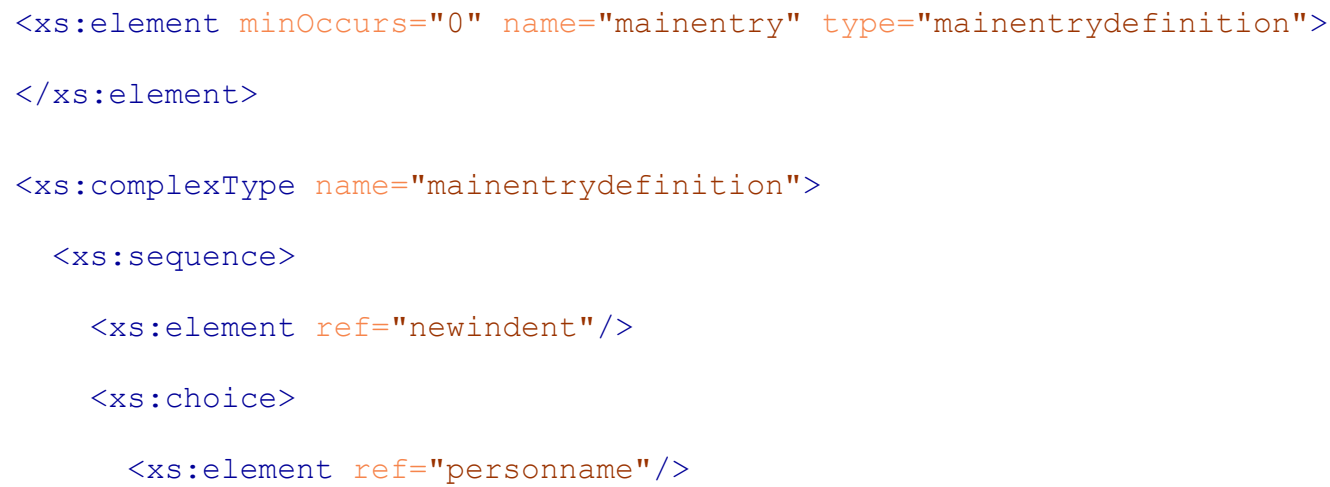


Metadata of posters in XML schema

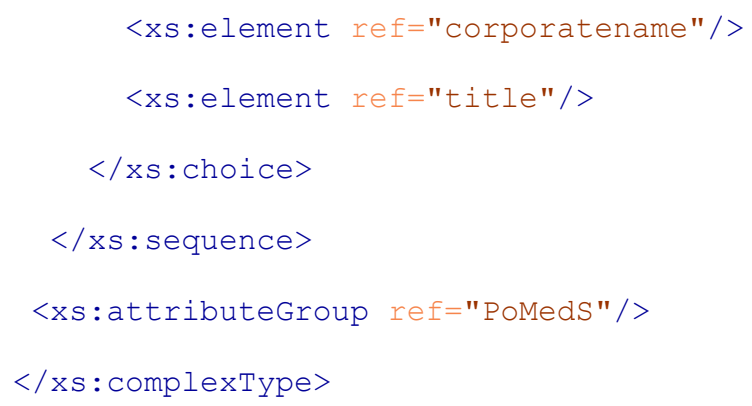

<titleandstatofresp> contains the PoMeDS elements corresponded to data of title and statement of responsibility where the title of poster and the contributors' names who participate in creation of the intellectual content of work are recorded.

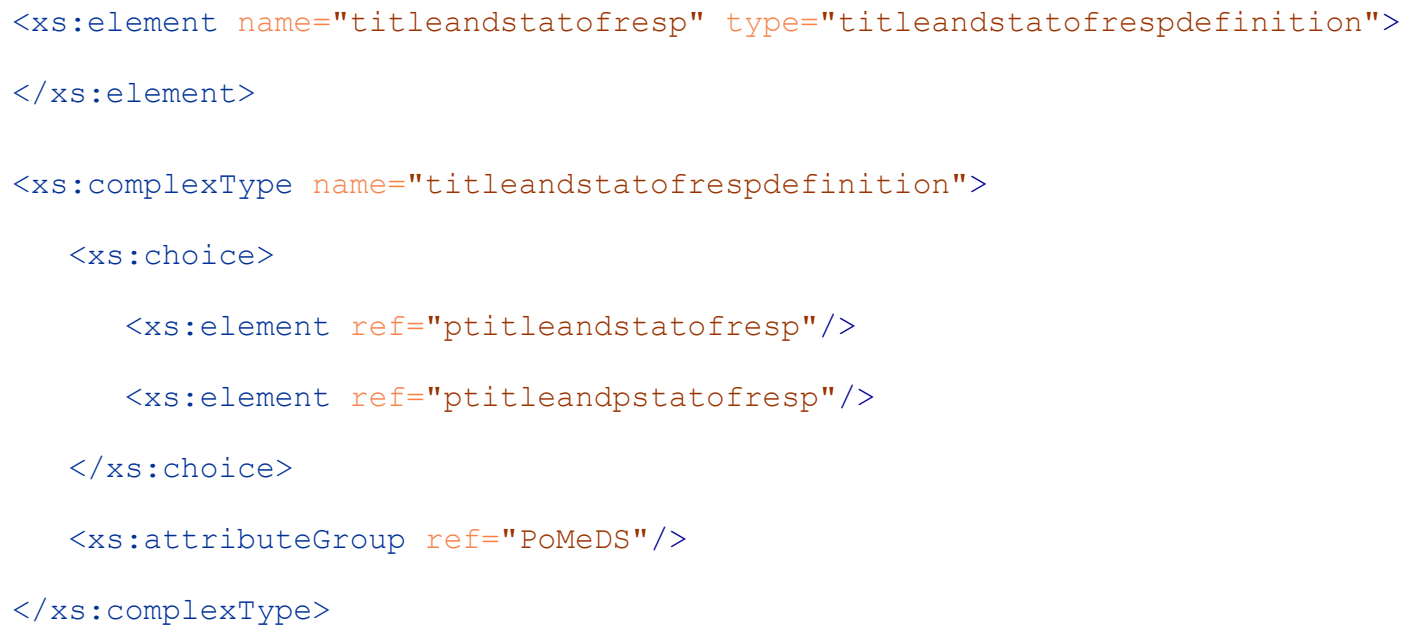

<edition> edition statement and statement of responsibility related to edition can be entered in this data group.

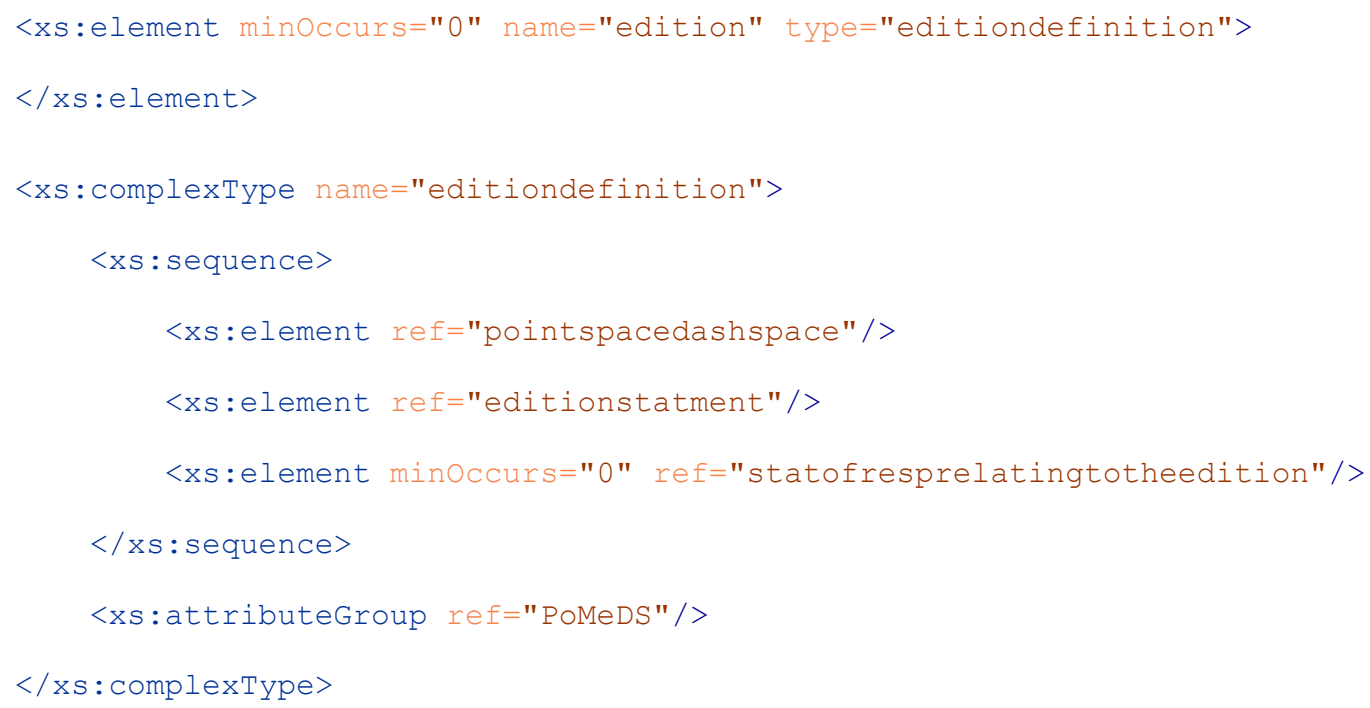


$<$ publication> includes data elements in connection with publication and distribution.

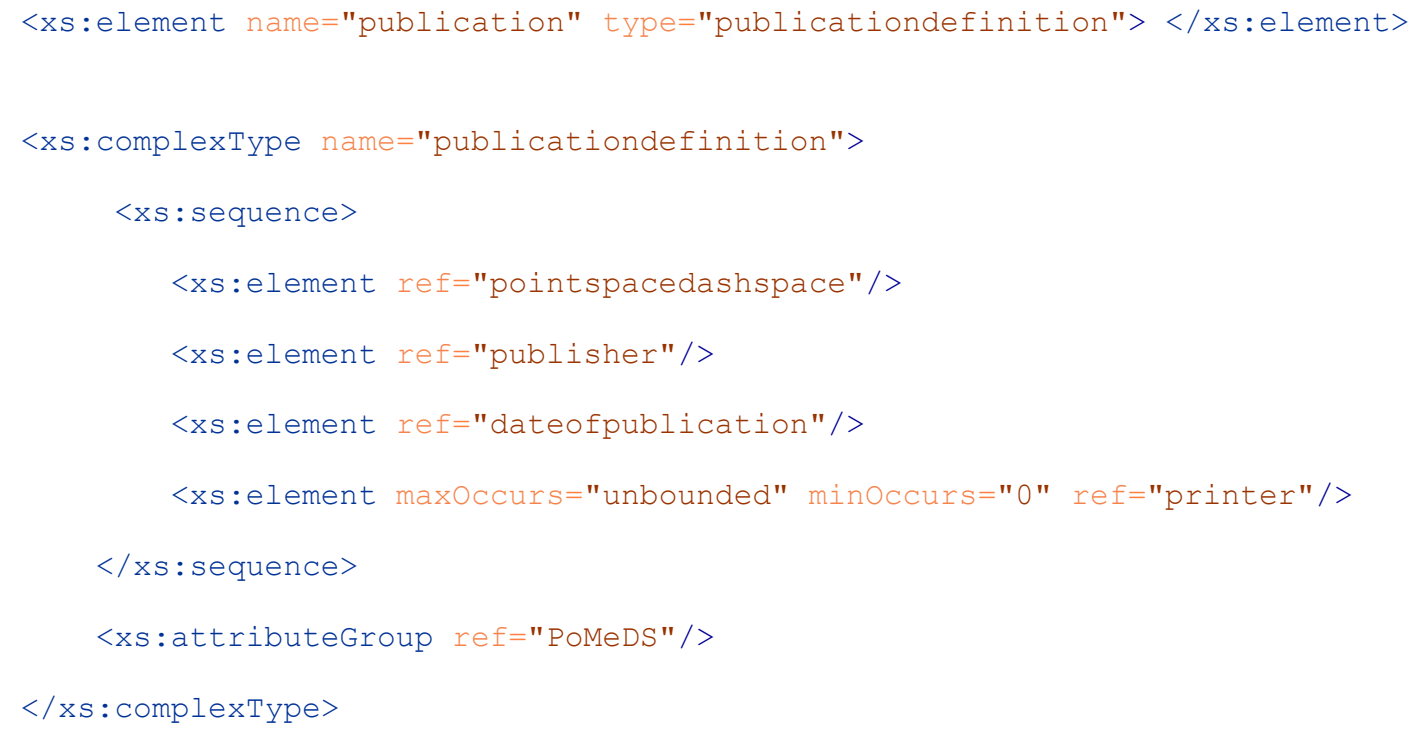

<physicaldescription> contains data connected with physical description like: number of physical units, other physical details (colours, manufacturing technique), dimension of a poster.

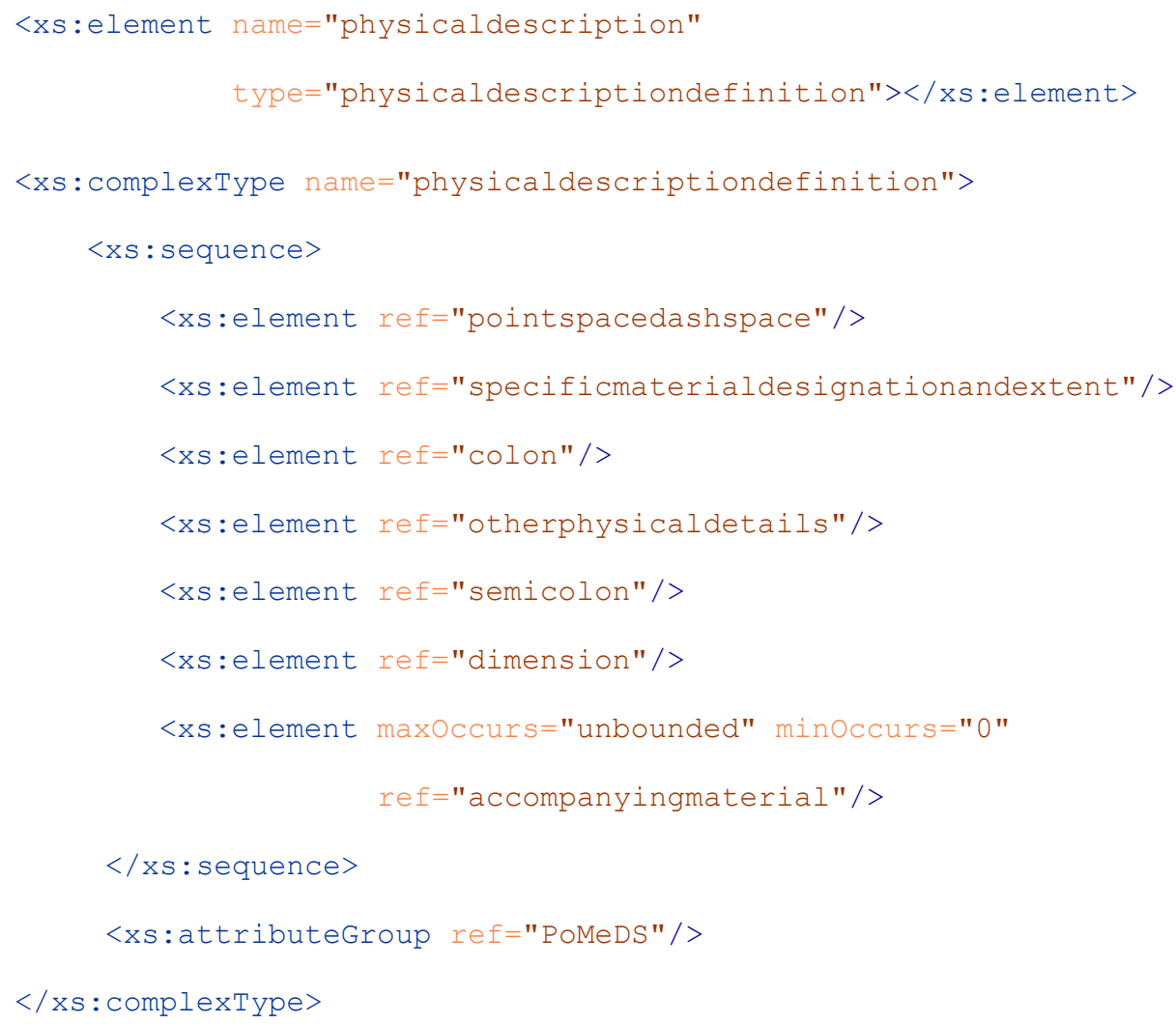


<series> if a poster is published as member of a series, then title and statement of responsibility of a series are recorded in this data group.

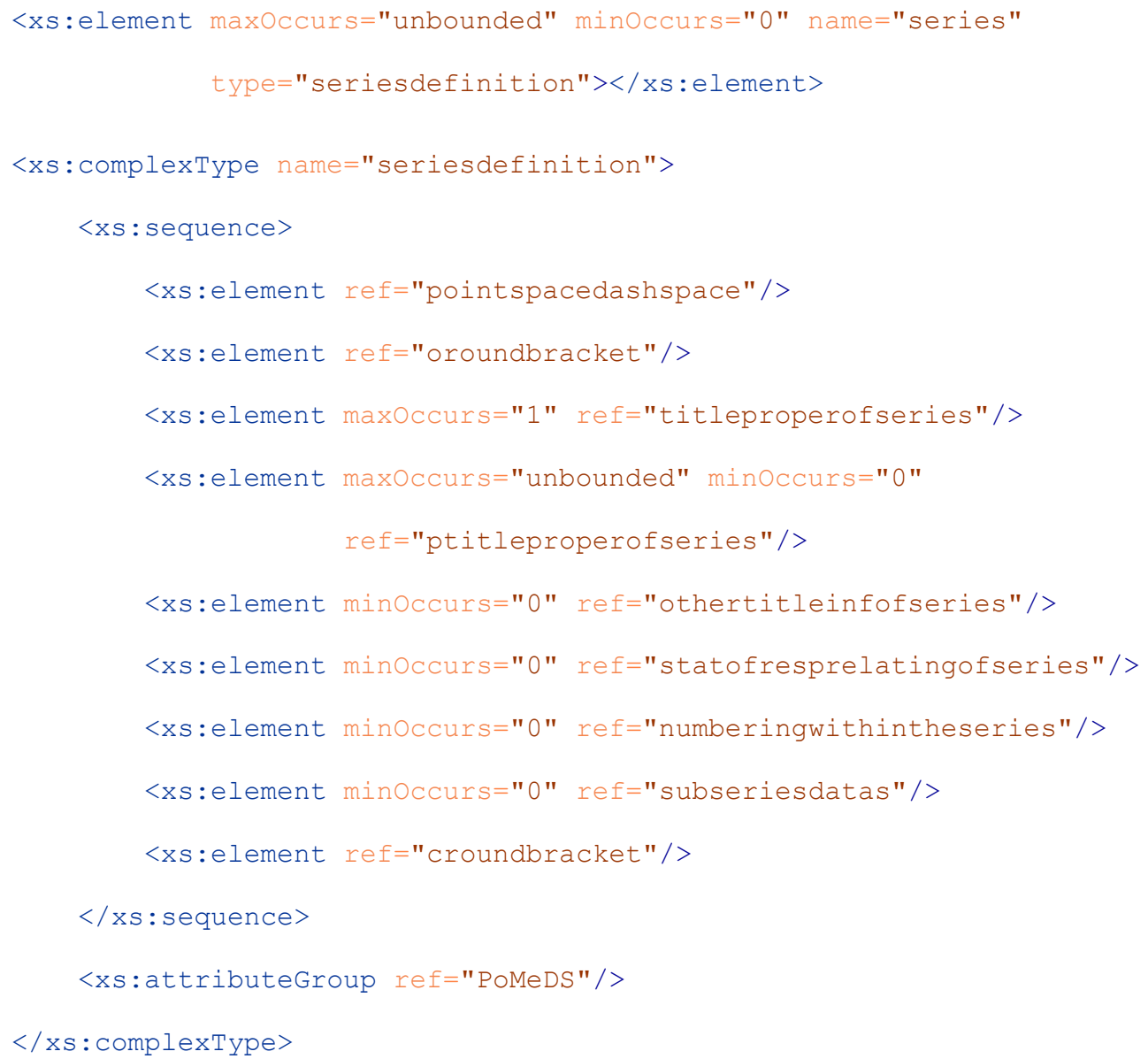

<notes $>$ includes additional, accurate information concerning bibliographic description and notes of a poster.

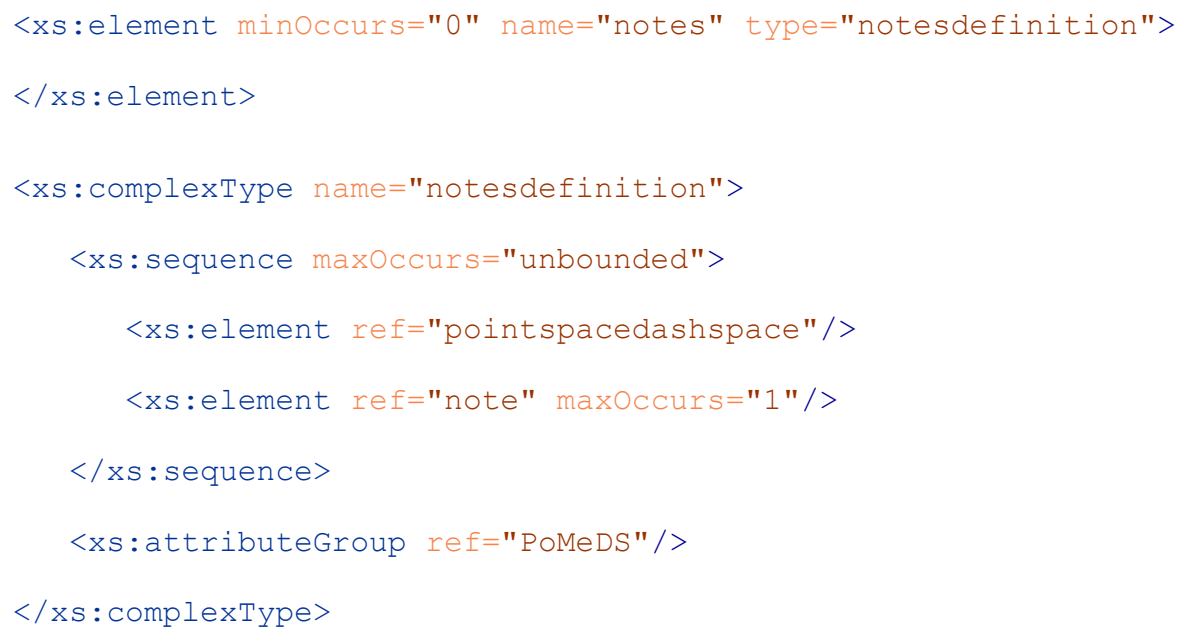


Metadata of posters in XML schema

<distributiondata $>$ contains data in relation to distribution of a poster.

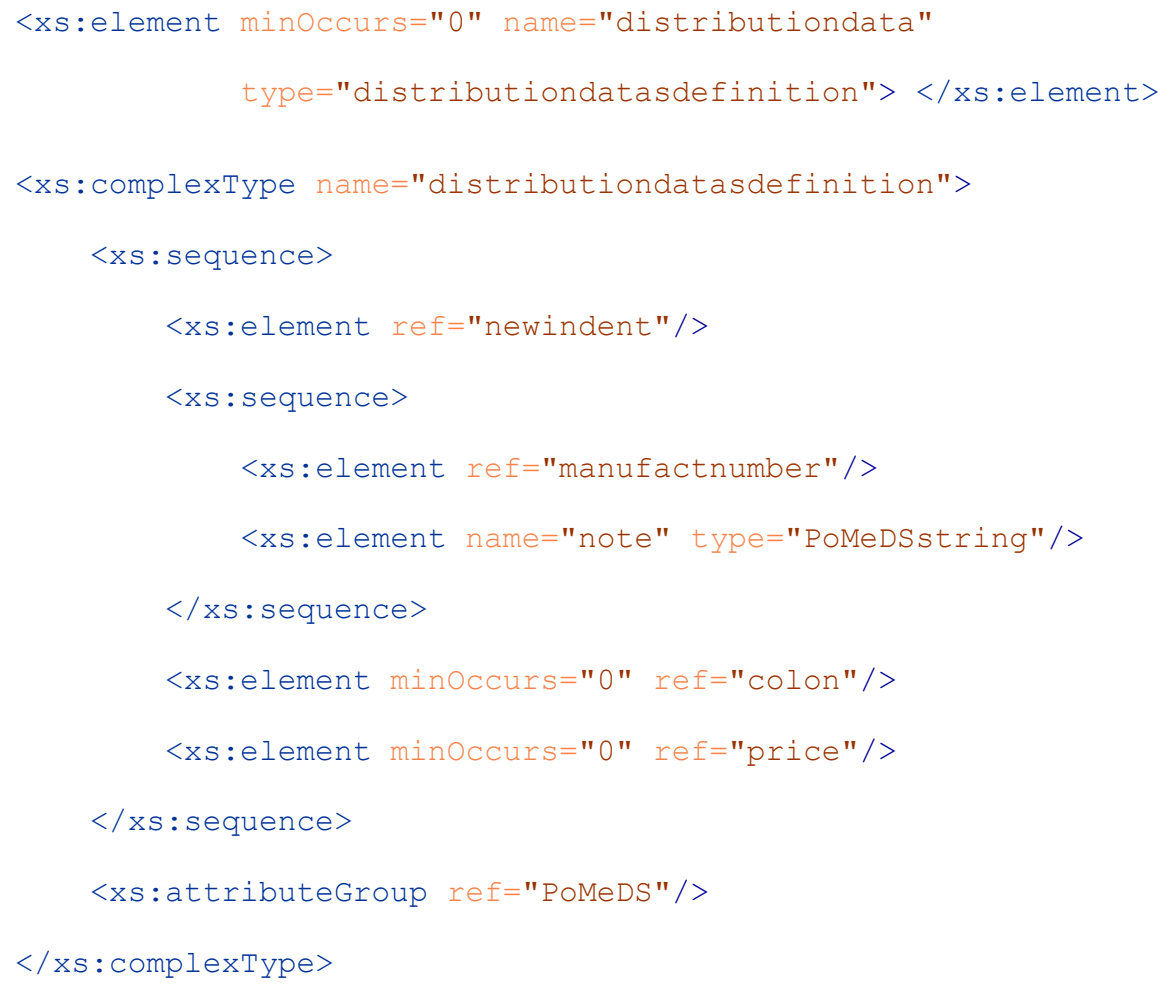

<subjectaddedentry> includes authoritative form of title and that of name of geographic location, meeting, corporate body and person in connection with the subject of a poster.

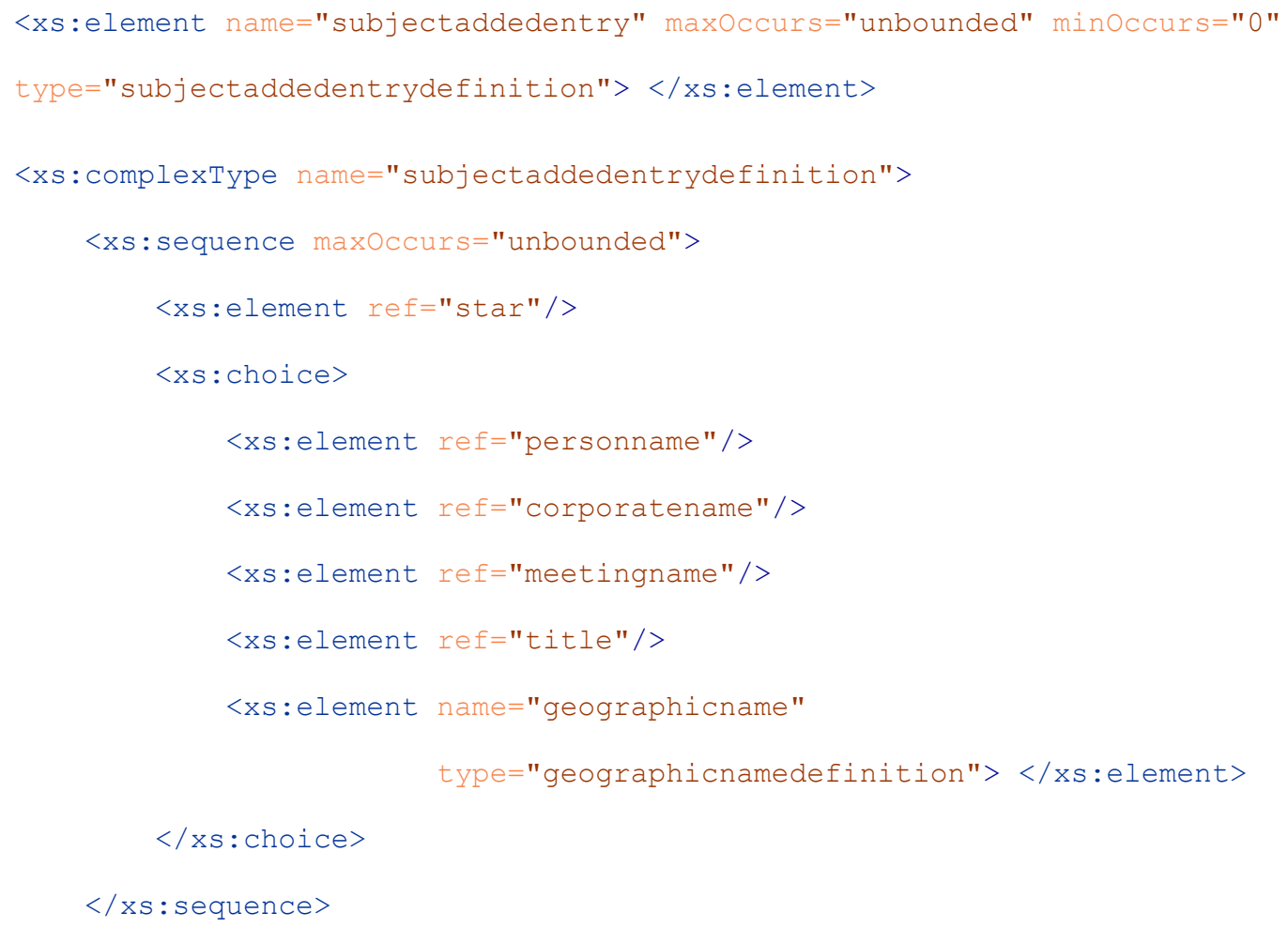




\section{Metadata of posters in XML schema}

<xs:attributeGroup ref="PoMeDS"/>

$</ x$ : complextype $>$

<subjectheading > contains subject headings expressing the content of a document.

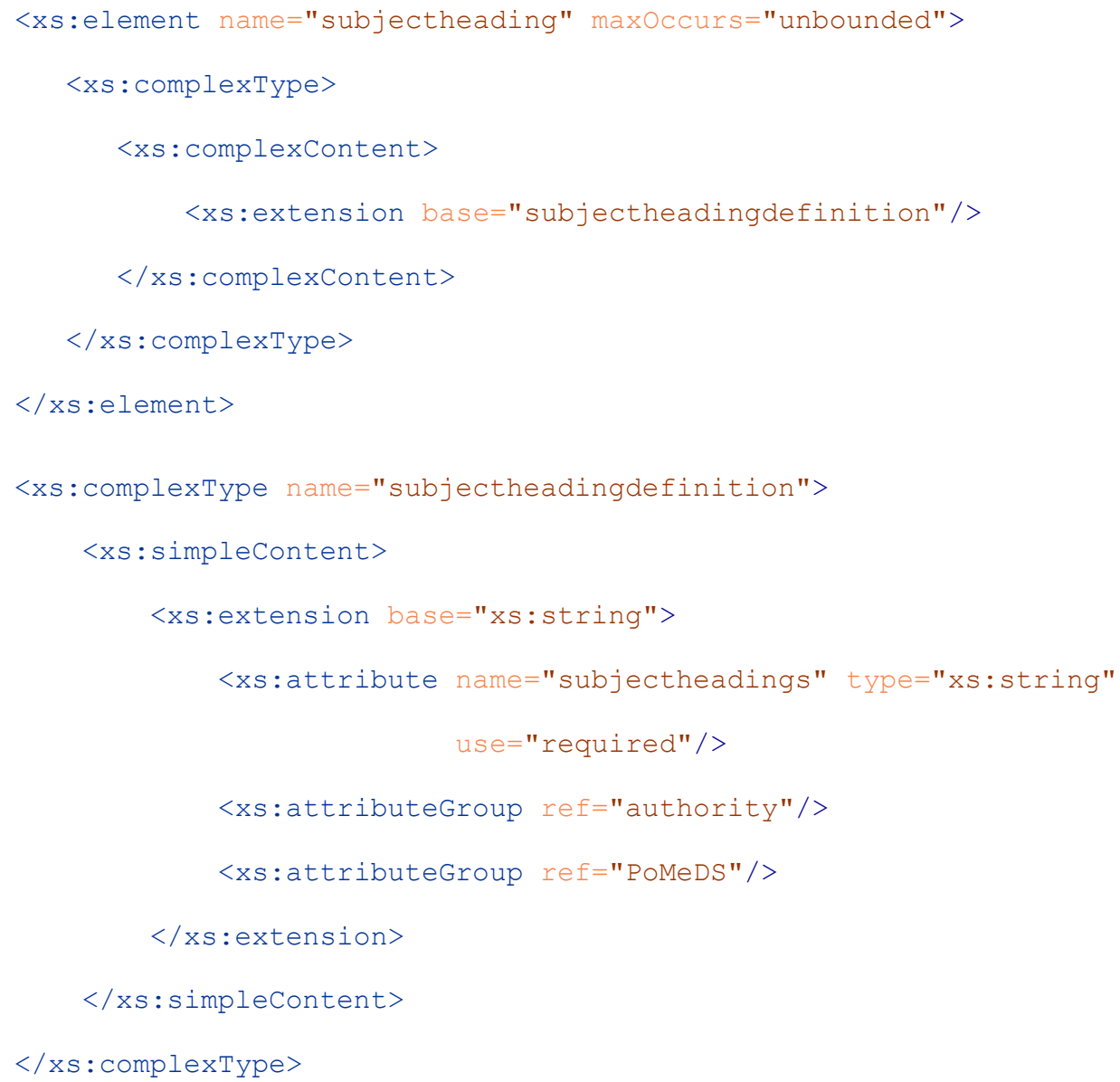

<addedentry > includes authoritative form of title and that of name of geographic location, meeting, corporate body and person.

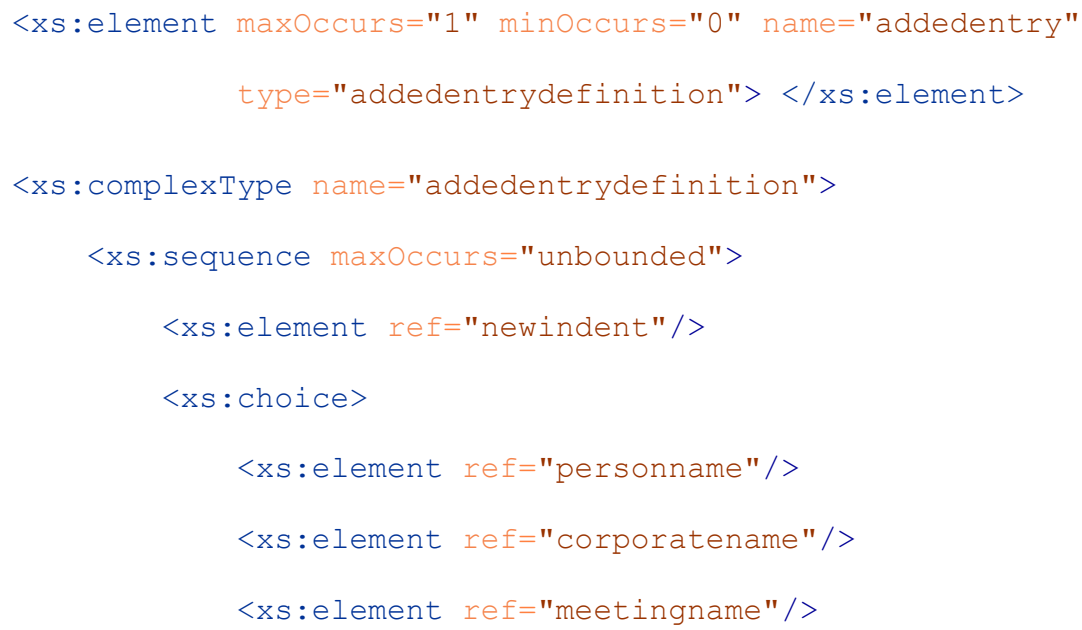


Metadata of posters in XML schema

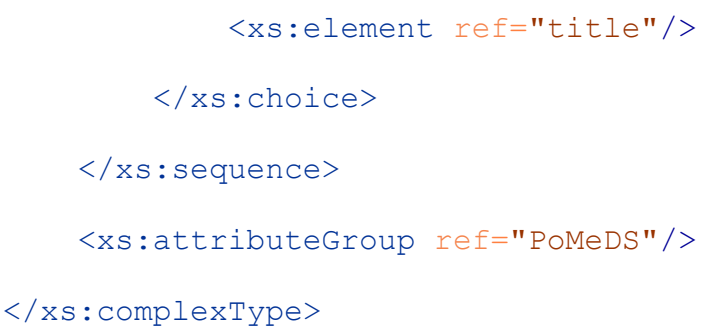

$<$ repository $>$ contains location information such as the name of institution preserving the poster, the name of collection within an institution and the call number of a poster.

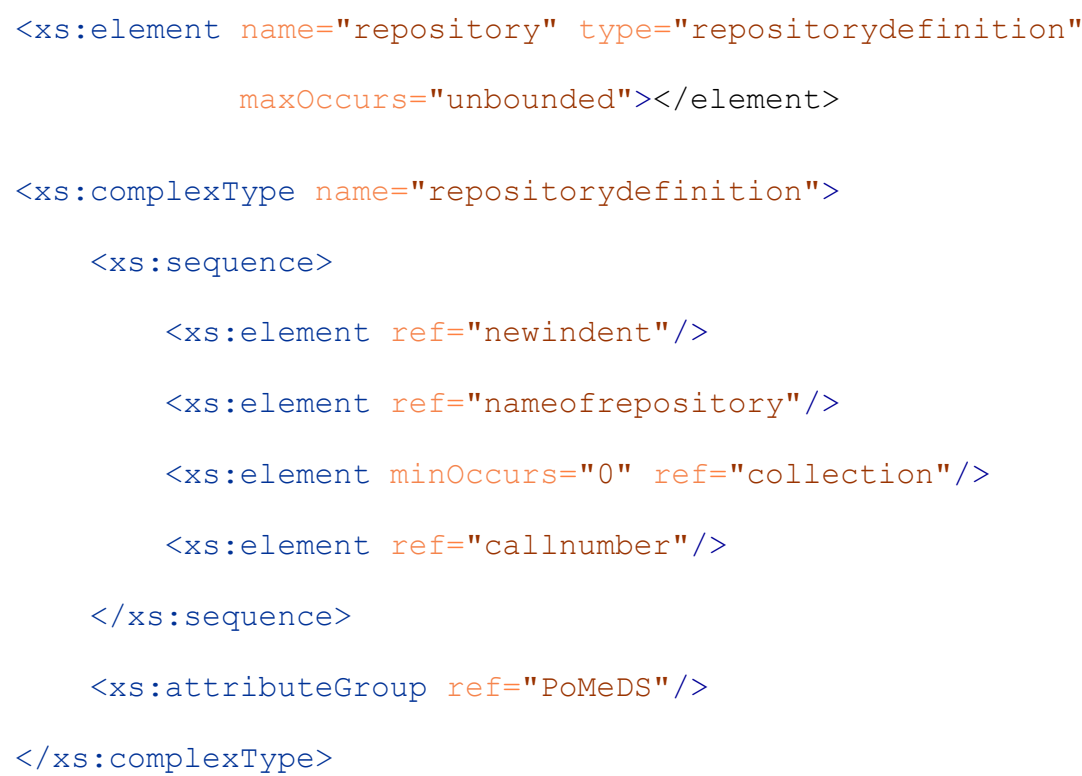

Concerning digitized posters data consist of two main parts: originalposter, digitizeddocument. The originalposter is made up of elements discussed before. These data are complemented with metadata characterizing the digitized version. These metadata can be found in the digitizeddocument element:

\section{1. figure: digitizeddocument element}

We can receive a more comprehensive overview of the structure of the PoMeDS through an example. We use an example of a commercial poster advertising Julius Meinl tea created by Otto Exinger. The bibliographic description of the printed poster is available in the online catalogue of the University and National Library University of Debrecen (UNL) and its 
Metadata of posters in XML schema

digitized version can be found in the University of Debrecen Electronic Archive (DEA). In the following section the bibliographic description of poster, a detail from the data of a digitized version and finally the data of a digitized poster in PoMeDS can be seen.

\section{2. figure: data of printed poster in MARC}

\section{1. table: data of a digitized poster}

\section{3. figure: data of a digitized poster in PoMeDS}

\section{Conclusions}

The PoMeDS is working with the secondary descriptive data of printed posters and the metadata of digitized posters. Corresponding to this, first I determined the metadata of printed posters. I began to determine this data when I was working at the Cataloguing Department of University of Debrecen University and National Library. At this time the cataloguing of posters has started. At a staff meeting my colleague reported her experiences in bibliographic description of posters and it has aroused my interest in the cataloguing of this document type. First I investigated the history of Poster Collection of University of Debrecen University and National Library by means of documents of records available in the library, but I am rather interested in cataloguing and metadata, for this reason I began to study the possibilities of bibliographic description of posters. Later I worked at Department of Library and Information Sciences of Faculty of Informatics of University of Debrecen, where I have been continuing my previous research and I have determined the metadata of digitized posters and have started to elaborate the PoMeDS. At present we can provide the bibliographic description of printed and digitized posters by using the PoMeDS. Further improvement of the schema is needed, as posters are created in computer-based systems too which sooner or later will be located in 
different collections as well. The elaboration of such a schema which supports the bibliographic description of digital posters may be a possible direction of further research.

\section{References:}

BETZ Elisabeth W. (1982). Grafic materials: rules for describing : original items and historical collections. Washington D.C.: Library of Congress. http://www.loc.gov/rr/print/gm/GraMatWP8.pdf

Coyle, K. (2005). Understanding metadata and its purpose. Journal of Academic Librarianship, 31.(2), p. 160-163. http://kcoyle.net/jal-31-2.html

Descriptive Metadata Guidelines for rlg cultural materials. http://oclc.org/content/dam/research/activities/culturalmaterials/RLG_desc_metadata.pdf

Dublin Core http://dublincore.org

ISBD(G): General International Standard Bibliographic Description (1977). London: IFLA Int. Office for UBC. http://archive.ifla.org/VII/s13/pubs/isbdg1.htm

ISBD(NBM): International Standard Bibliographic Description for Non-Book Materials (1987). London: IFLA Universal Bibliographic Control and International MARC Programme British Library Bibliographic Services.

http://www.ifla.org/files/assets/cataloguing/isbd/isbd-nbm_1987.pdf

Library of Congress Cataloging and Acquisitions Home. http://www.loc.gov/aba/

Metadata Object Description Schema (MODS). http://www.loc.gov/standards/mods/

Miller, Steven J. (2011). Metadata for digital collections. New York: Neal-Schuman. 
MSZ 3424/1. Bibliográfiai leírás. Könyvek

NISO Metadata for Imagesin XML Schema (MIX). http://www.loc.gov/standards/mix//

Online Cataogue of University of Debrecen University and National Library.

http://webpac.lib.unideb.hu/WebPac/

Orosz M. (2005). A plakát születése: egy új müfaj keresi a nyelvét. Budapest: ELTE BTK Művészettörténeti Intézet.

Salgáné Medveczki M. (2006). Egy új jelölö nyelv (metaadat-rendszer) kidolgozása a számítógépes bibliográfiai adatfeldolgozáshoz. PhD értekezés. Debrecen: Debreceni Egyetem.

Szenteczki Cs. (2003). A nyomtatott grafika története és technikái. Budapest: Müszaki Könyvkiadó.

University of Debrecen Electronic Archive. https://dea.lib.unideb.hu/dea/

Varga I. (1981). Állóképek bibliográfiai leírása: útmutató. Budapest: OSZK-KMK.

VRA Core http://www.vraweb.org/projects/vracore4

XML Schema http://www.w3.org/XML/Schema

Zala T. (1997). A grafika története. Budapest: TAN-GRAFIX. 
Metadata of posters in XML schema

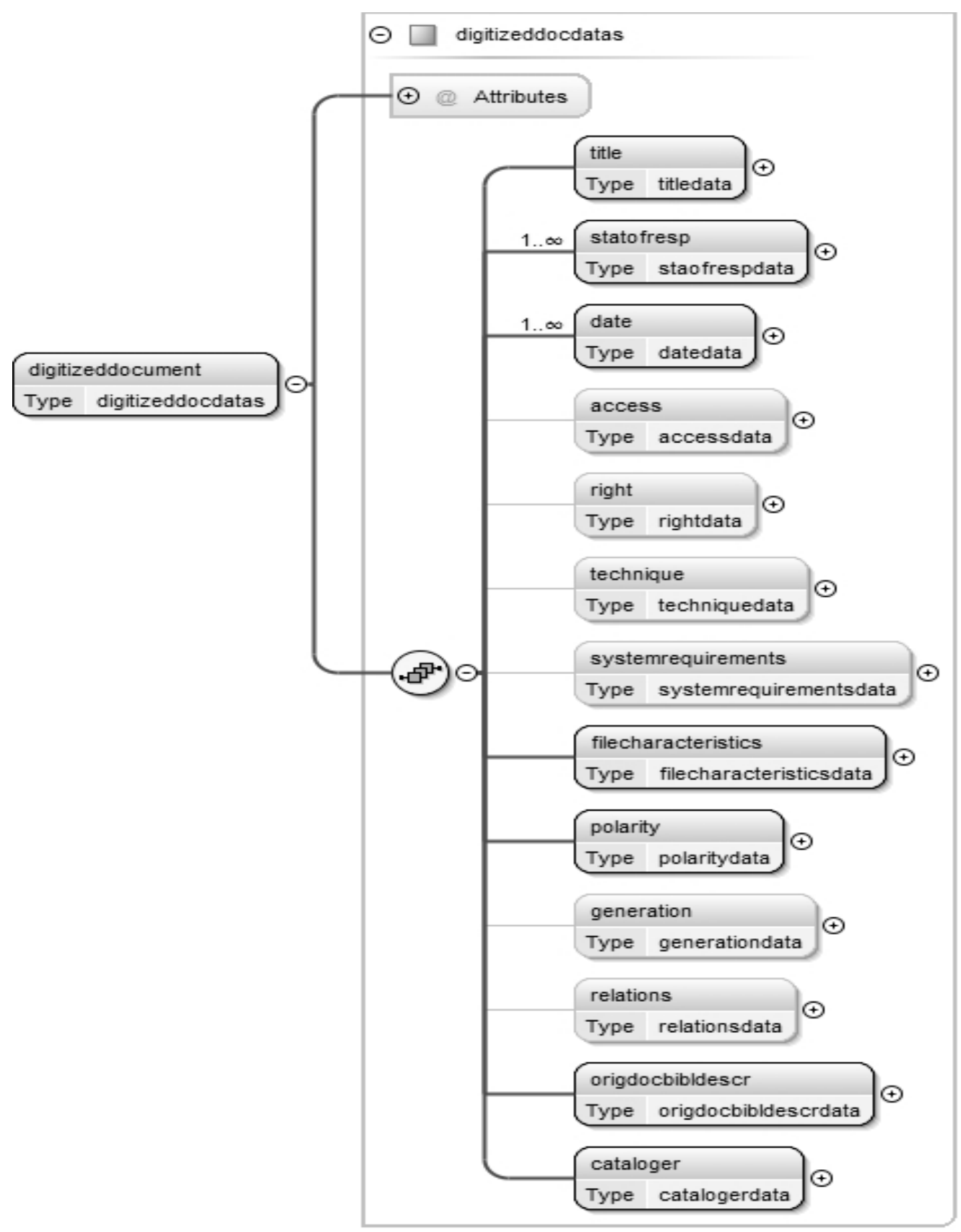

1. figure: digitizeddocument element 
Metadata of posters in XML schema

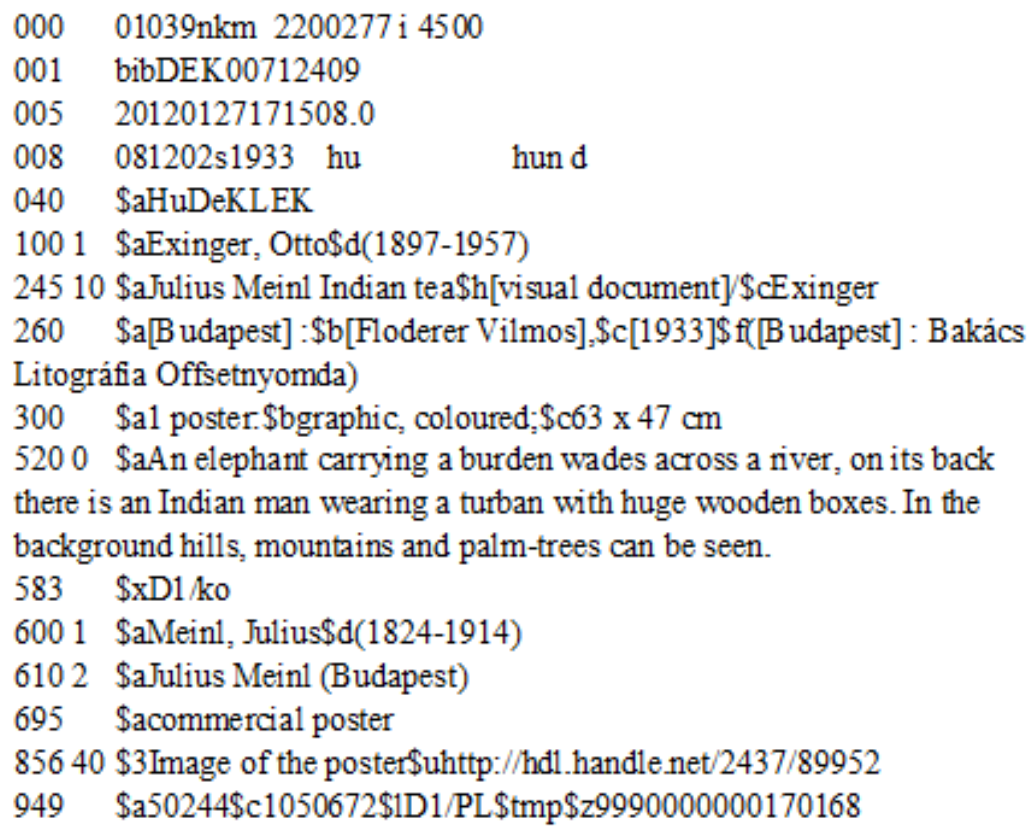

2. figure: data of printed poster in MARC 


\section{Metadata of posters in XML schema}

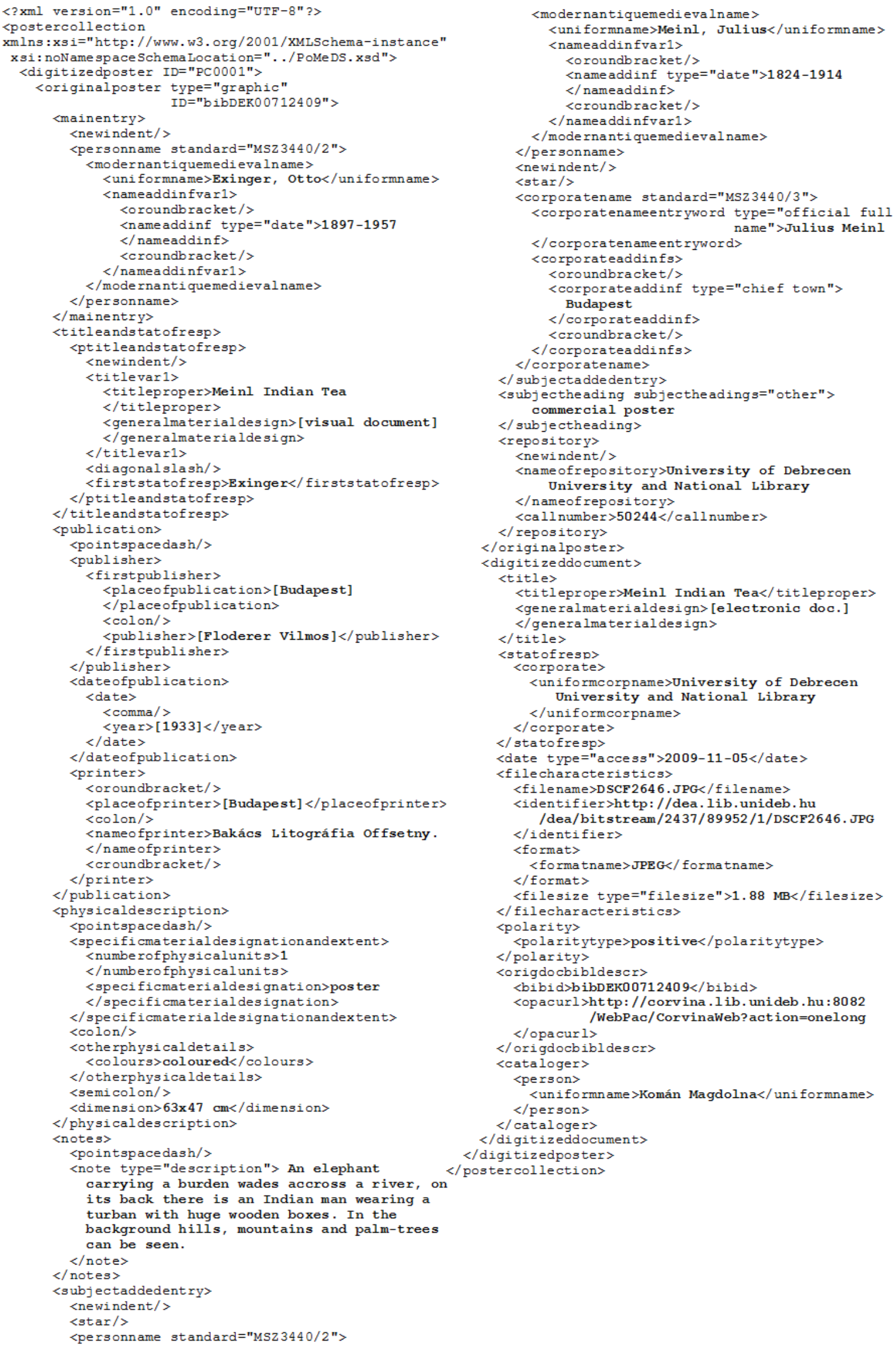

\section{3. figure: data of a digitized poster in PoMeDS}

